\title{
PEMANFAATAN TEKNOLOGI ECO PUSH BUTTON SEBAGAI PENGAMAN BOX BRANKAS BERBASIS ATMEGA 16
}

\author{
Mufti fathlillah ${ }^{1}$, Achmad Zakki Falani ${ }^{2}$ \\ Fakultas Ilmu Komputer Jurusan Sistem Komputer, Universitas Narotama Surabaya \\ ${ }^{1}$ muftigrand@gmail.com, ${ }^{2}$ achmad.zakki@narotama.ac.id
}

\begin{abstract}
Abstrak
Masyarakat yang mempunyai banyak berkas atau dokumen yang penting semisal mempunyai perusahaan, memang sudah saatnya untuk memberikan suatu keputusan dimana penyimpanan berkas tersebut, di samping di bank, jika dokumen tgersebut sering di gunakan maka harus disimpan di rumah atau kantor agar dapat mudah mengambil data tersebut tanpa pergi ke bank, di samping untuk menghemat dana operasional bagi perusahaan dengan begitu dapat meminimalisir kehilangan suatu berkas atau dokumen yang sudah di simpan, masyarakat sebenarnya sudah mengetahui mengenai tempat penyimpanan ini, akan tetapi masyarakat kurang menyadari betapa penting tempat penyimpanan ini. Pada sebuah kotak penyimpanan pada umumnya menggunakan analog dengan angka - angka dan kunci,dengan ini memberikan suatu pengembangan model yang akan berkembang di kemudian hari berkenaan dengan mempermudah suatu sistem yang dapat kita pakai bertujuan untuk mempermudah dan mengurangi resiko terjadinya kerusakan kunci di kotak pengamanan yang di dalamnya ada berbagai benda atau file yang hanya dapat di buka oleh orang - orang tertentu saja, dengan menggunakan suatu ekonomis Push Button sebagai pengganti kunci dan memasukkan password untuk membuka kotak tersebut.
\end{abstract}

Kata Kunci : $\quad$ Eco Push Button, Menggunakan ATMega 16.

\subsection{Latar Belakang}

Kesadaran masyarakat saat ini juga mulai meningkat dimana pada saat penyimpanan dokumen atau berkas tertentu, dari mulai di simpan di dalam map, di tas, atau di dalam kotak yang berisi dokumen atay berkas yang penting, benda yang berupa kertas dan mudah lusuh seharusnya memang disimpan di tempat yang aman dan mempunyai perlindungan khusus demi ke selamatan dokumen tersebut.

Masyarakat yang mempunyai banyak berkas atau dokumen yang penting semisal mempunyai perusahaan, memang sudah saatnya untuk memberikan suatu keputusan dimana penyimpanan berkas tersebut, di samping di bank, jika dokumen tgersebut sering di gunakan maka harus disimpan di rumah atau kantor agar dapat mudah mengambil data tersebut tanpa pergi ke bank, di samping untuk menghemat dana operasional bagi perusahaan dengan begitu dapat meminimalisir kehilangan suatu berkas atau dokumen yang sudah di simpan, masyarakat sebenarnya sudah mengetahui mengenai tempat penyimpanan ini, akan tetapi masyarakat kurang menyadari betapa penting tempat penyimpanan ini. Yaitu adalah Brankas adalah lemari atau kotak yang biasa dipergunakan untuk melindungi barang-barang berharga dari pencurian/pembongkaran (seperti uang, surat-surat berharga, perhiasan, dll).

\subsection{Rumusan Masalah}

adalah:

Perumusan masalah dari penelitian ini

1. Bagaimana perkembangan yang sangat membatu untuk kotak penyimpanan yang minimalis serta ringan akan tetapi dapat di patenkan untuk penempatannya dan tidak dapat di pindah dengan cara dibor pada pojok sisi yang ada di bawah brankas tersebut.

2. Dengan menggunakan metode pembuka dengan cara mekan tombol yang pada biasanya di brankas tidak ada demi terwujudnya untuk mengurangi biji besi pengganti kunci.

3. Dengan tambahan ada kode tersendiri melalui keypad dan di tampilkan ke LCD memasukkan kode pin agar dapat membuka brankas tersebut, ini sebagai pengaman agar tidak semua orang dapat membuka.

4. Media penyimpanan yang sangat minimalis dapat diterapkan oleh semua kalangan umum dimana 
membutuhkan suatu tempat penyimpanan berkas yang di anggap berkas itu penting.

\subsection{Batasan Masalah}

Batasan masalah yang dibahas dalam

Penelitian ini adalah:

1. Kotak penyimpanan ini hanya menggunakan tombol untuk dapat mengakses masuk kedalam kode pin dan akan tampil masukkan kode kepada $L C D$ kemudian menekan kode melalui media keypad sehingga mempermudah pengguna.

2. Dalam rangkaian kali ini system minimumnya menggunakan ATMEGA 16 yang sudah banyak di pakai oleh rangkaian system minimum pada umumnya.Penyimpanan benda kecil berukuran kotak $8 \times 11$ inch setara dengan kertas berukuran A4, atau menyimpan berkas dengan ukuran kertas A4, untuk kotak tampilan yang sederhana.

\subsection{Pengertian Sistem}

Dalam mendefinisikan pengertian dari sistem ada dua kelompok pendekatan yaitu menekankan pada prosedurnya dan menekankan pada komponen elemennya. Pendekatan sistem yang lebih menekankan pada prosedurnya mendefinisikan sistem adalah suatu jaringan kerja dari prosedur - prosedur yang saling berhubungan berkumpul bersama - sama untuk melakukan suatu kegiatan atau untuk menyelesaikan suatu masalah. (Jogiyanto, 2001). Sistem itu adalah suatu kumpulan atau variabel yang terorganisasi, saling berinteraksi, saling bergantung satu sama lain dan terpadu.

\subsection{Kriteria Sistem yang baik}

Kegunaan Sistem harus menghasilkan informasi yang tepat waktu dan relevan untuk proses pengambilan keputusan manajemen dan personel operasi di dalam organisasi. Ekonomis, semua bagian sistem termasuk laporan, pengawasan dan lain sebagainya harus menyumbangkan suatu nilai plus sekurang - kurangnya sebesar atau sesuai dengan biayanya.

\subsection{Elemen - Elemen Sistem}

Merupakan tujuan akhir atau sasaran dari pengolahan sistem tersebut yang dapat berupa : Tujuan usaha, Kebutuhan, Masalah, Prosedur pencapaian tujuan. Batasan merupakan daerah yang membatasi antara satu sistem dengan sistem yang lain atau dengan lingkungan luarnya sehingga memungkinkan suatu sistem dipdanng sebagai satu kesatuan dalam sebuah ruang lingkup. Batasan batasan sistem dapat berupa: Peraturan, Biaya, Personel, Peralatan. Keterkaitan elemen - elemen yang terdapat pada sistem dapat dilihat pada gambar berikut:

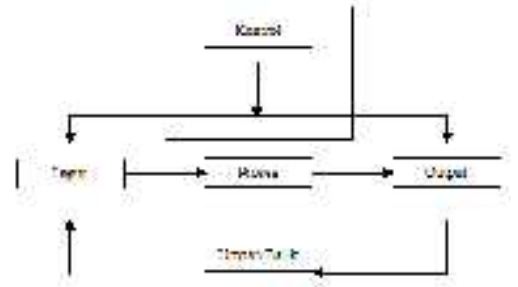

Gambar 2.1. Keterkaitan Elemen - Elemen Dalam Sistem

Sebagai sesuatu yang dinamik, sebuah sistem memiliki tingkah laku yang berbeda dari satu sistem dengan sistem yang lain. Berdasarkan pola tingkah laku, terdapat 4 jenis sistem yaitu :

1. Deterministic System :

Adalah sistem dimana segala tingkah lakunya dapat diramalkan.

2. Probabilistic System

Adalah sistem dimana segala tingkah lakunya tidak dapat diramalkan.

3. Closed System

Adalah sistem yang tidak mempunyai relasi atau hubungan dengan lingkungan.

4. Open System

Adalah sistem yang mempunyai relasi atau hubungan dengan lingkungan.

\subsection{Code Vision AVR}

CodeVision AVR merupakan sebuah software yang digunakan untuk memprogram mikrokontroler sekarang ini telah umum. Mulai dari penggunaan untuk kontrol sederhana sampai kontrol yang cukup kompleks, mikrokontroler dapat berfungsi jika telah diisi sebuah program, pengisian program ini dapat dilakukan menggunakan compiler yang selanjutnya didownload ke dalam mikrokontroler menggunakan downloader. 


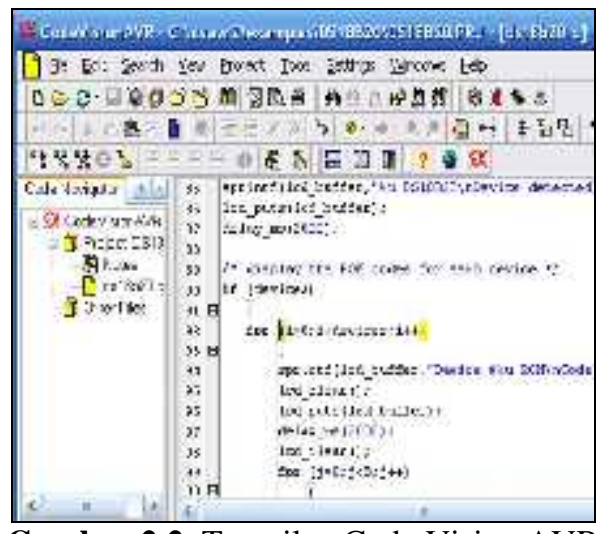

Gambar 2.2. Tampilan Code Vision AVR

\subsection{Push Button}

Pengrtian dasar Otomatis. sering Di dalam dunia modern yang mengedepankan kenyamanan dan kecepatan, sistem yang bekerja secara otomatis akan semakin banyak. Otomatis sering kali diartikan sebagai "tidak menggunakan tenaga manusia". Namun apakah arti otomasi? Menurut WordNet @ 2.0, () 2003 Princeton University, berikut ini pengertian otomasi.

\subsection{Keypad}

Keypad adalah sebuah rangkaian tombol yang berfungsi untuk member signal pada suatu rangkaian dengan menghubungkan jalur - jalur tertentu, Keypad terdiri dari beberapamacam berdasarkan jumlah tombol dan fungsinya. Pada sistem pengontrolan ini, digunakan keypad matriks 3x4 ( 12 saklar ) dengan pin penghubung rangkaian berjumlah 7 buah.

\begin{tabular}{|c|c|c|}
\hline 1 & 2 & 3 \\
\hline 4 & 5 & 6 \\
\hline 7 & 8 & 9 \\
\hline$*$ & 0 & $\#$ \\
\hline
\end{tabular}

Gambar 2.3. Tampilan Fisik Keypad $3 \times 4$

\subsection{Liquid Crystal Display ( LCD )}

LCD (Liquid Cristal Display) berfungsi untuk menampilkan karakter angka, huruf ataupun simbol dengan lebih baik dan dengan konsumsi arus yang rendah. LCD (Liquid Cristal Display) dot matrik M1632 merupakan modul LCD buatan hitachi. Modul LCD (Liquid Cristal Display) dot matrik M1632 terdiri dari bagian penampil karakter (LCD) yang berfungsi menampilkan karakter dan bagian sistem prosesor LCD dalam bentuk modul dengan mikrokontroler yang diletakan dibagian belakan LCD tersebut yang berfungsi untuk mengatur tampilan LCD serta mengatur komunikasi antara LCD dengan mikrokontroler yang menggunakan modul LCD tersebut.

\subsection{AVR ATMega 16}

AVR merupakan seri mikrokontroler CMOS 8-bit buatan Atmel, berbasis arsitektur RISC (Reduced Instruction Set Computer). Hampir semua instruksi dieksekusi dalam satu siklus clock. AVR mempunyai 32 register general-purpose, timer/counter fleksibel dengan mode compare, interrupt internal dan eksternal, serial UART, programmable Watchdog Timer, dan mode power saving, ADC dan PWM internal. AVR juga mempunyai In-System Programmable Flash on-chip yang mengijinkan memori program untuk diprogram ulang dalam system menggunakan hubungan serial SPI. ATMega16.

\subsection{Konektifitas Serial Dengan PC}

Komunikasi Serial dengan PC adalah komunikasi serial yang menggunakan stdanrd komunikasi RS 232 untuk di hubungkan ke PC.

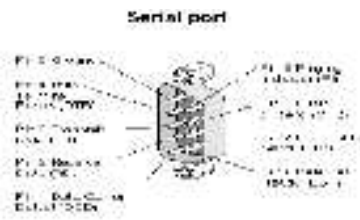

Gambar 2.4. Konfigurasi serial DB 9

\subsection{Solenoid}

Solenoid adalah aktuator mampu gerakan linier. solenoid dapat elektromekanis (AC / DC), hidrolik, pneumatik atau didorong - semua operasi pada prinsip-prinsip dasar yang sama. Dengan memberikan sumber tegangan maka solenoid dapat menghasilakan gaya yang linier. Contohnya untuk menekan tombol, memukul tombol pada piano, operator katup, dan bahkan untuk robot melompat. Solonoids DC beroperasi pada prinsipprinsip seperti motor DC. Perbedaan antara solenoida dan motor adalah bahwa solenoid adalah motor yang tidak dapat berputar. 


\subsection{Software Eagle Profesional 5}

EAGLE memungkinkan pengguna untuk menyesuaikan tertentu fitur program, seperti konfigurasi menu, tombol fungsi, atau warna layar. Banyak pengaturan ini dapat dilakukan di menu Options di Control Panel atau di salah satu jendela Editor. The Script eagle.scr Berkas Dalam file perintah khusus (file script) eagle.scr nilai preset untuk Schematic, Layout, dan Perpustakaan Editor dapat dimasukkan dalam bentuk EAGLE perintah. Sintaks setiap EAGLE Perintah dijelaskan dalam bantuan EAGLE.

\subsection{Perancangan Sistem}

Dalam pelaksanaan pembuatan alat maka digunakan beberapa cara sebagai berikut : Tahapan persiapan studi literatur melihat suatu perkembangan kotak penyimpanan dan melanjutkan ke proses pembuatan. Tahap perancangan erancang rangkaian elektronika yang berupa power supply, rangkaian mikrokontroler, driver solenoid, rangkaian $L C D$, pushbutton. Tahap pembelian komponen membeli komponen-komponen yang dibutuhkan untuk tahap perancangan dan pembuatan.

Tahap pembuatan atau perakitan rangkaian elektronik yang telah direncanakan seperti power supply, rangkaian mikrokontroler, driver solenoid, rangkaian $L C D$, pushbutton.

\subsection{Rangkaian}

Adapun untuk rangkaian yang sudah di rangcang yaitu sebagai berikut:

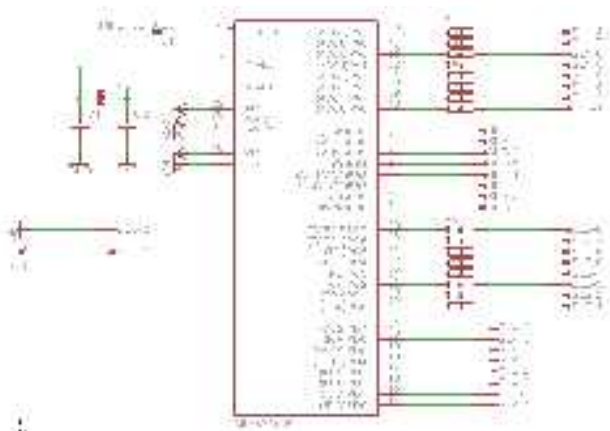

Gambar 3.1. Rangkaian Sistem Minimum

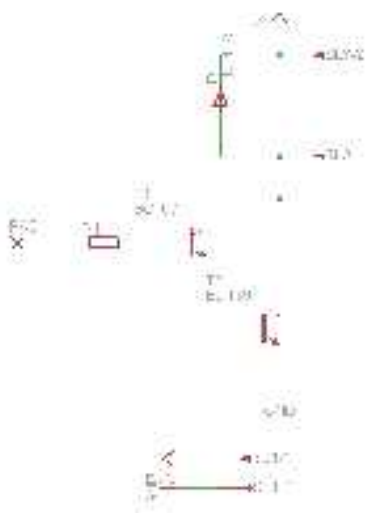

Gambar 3.2. Rangkaian Driver Solenoid

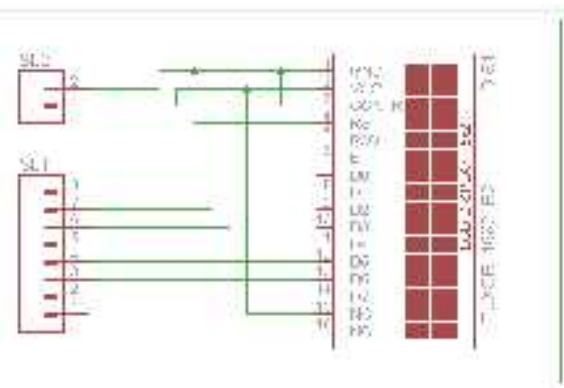

Gambar 3.3. Rangkaian $L C D$

\subsection{Analisa Sistem}

Efektif dan kemudahan alat ini sangat diutamakan. Dari beberapa susunan rangkaian, dari mulai rangkaian power, rangkaian sistem minimun, dan rangkaian solenoid menjadikan suatu kesatuan proyek pembuatan kotak penyimpanan yang sangat use friendly untuk kalangan orang umum.

\subsection{Pengenalan Aplikasi}

Dalam aplikasi yang di luncurkan oleh EAGLE 5 professional membuat suatu rangakaian PCB dari seluruh rangkaian yang di buat oleh menyatukan model rangkaian dari rangkaian power, rangkaian sistem minimun dan rangkaian solenoid. Dengan begitu akan menjadikan suatu rangkaian kotak penyimpanan.

\subsection{Pengujian Rangkaian}

Berikut adalah tahapan dari pengujian rangkaian:

1. Pengujian system minimum, yakni mengisikan program pada microcontroller AVR dengan bahasa $\mathrm{C}$ serta mengukur tegangan pin I/O pada saat berlogika 1 dan 0 . 
2. Pengujian Keypad dengan cara mencoba konfigurasi input dan output.

3. Pengujian LCD, dengan mengetahui apakah LCD bisa berfungsi dengan baik.

4. Pengujian Solenoid, untuk mengetahui apakah driver solenoid bisa berfungsi dengan baik.

5. Pengujian Keseluruhan

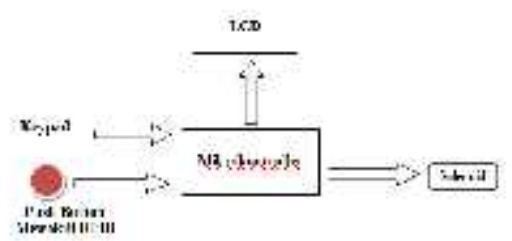

Gambar 4.1. Rangkaian pengujian system keseluruhan

\subsection{Kesimpulan}

Dari hasil penjabaran diatas, maka dapat diambil kesimpulan sebagai berikut :

1. Rancangan Penelitian

Penelitian yang akan dilakukan berupa pembuatan rangkaian yang di jadikan satu antaranya power, system minimum, dan solenoid yang akan bekerja dengan sesuai fungsi masing - masing rangkaian yang menjadikan rangkaian suatu kotak penimpanan.

2. Analisis, Perancangan dan Simulasi

Setelah mempelajari buku-buku dan website yang terkait dengan permasalahan yang akan dibahas, sebelum mengimplementasikan dalam bentuk simulasi, terlebih dahulu dibuat rancangan sistemnya. Setelah didapatkan rancangan model dari sistem yang sesuai, kemudian diimplementasikan ke dalam simulasi yaitu membuat sistem, mulai dari rangkaian elektroniknya, kemudian perangkat lunak, dan komponen.

3. Evaluasi

Setelah selesai pembuatan sistem, tahap berikutnya adalah menguji sistem, apakah sudah dapat bekerja sesuai dengan apa yang diharapkan atau tidak. Bila dalam proses pengujiannya masih terdapat beberapa kesalahan, maka selanjutnya akan dilakukan perbaikan-perbaikan sampai tidak ada kesalahan lagi. Hal-hal yang dilakukan dalam proses pengujian adalah menguji apakah rangkaian yang dibuat sudah bekerja dengan baik. Sehingga bila simulasi dijalankan, akan didapatkan hasil yang diinginkan.

\subsection{Saran}

Penelitian ini sangat jauh dari kata yang smpurna, maka penulis mengharapkan agar di kemudian hari dapat di kembangkan dengan cara yang lebih detail dan lebih banyak fungsi sehingga tidak ada untuk kekurangan suatu system tersebut dan suatu rangkaian terseut juga jauh dari kesempurnaan, maka penulis sangat berterima kasih jika metode akan di kembangkan lebih bagus dan dapat di gunakan oleh khalayak umum yang sangat sempurna.

\section{Daftar Pustaka}

Al Fatta, Hanif, 2007, Analisa \& Perancangan Sistem Informasi, Jogjakarta : ANDI.

Andrianto,Heri.2008. Pemrograman Mikrokontroler AVR ATmega16 Menggunakan Bahasa C. Bandung: Penerbit Informatika.

Bejo, Agus. 2007. C \& AVR'Rahasia Kemudahan Bahasa C Dalam Mikrokontroler ATmega8535'. Yogyakarta: Graha Ilmu.

Budhiarjo,sugeng,2009,http://www.elektronikamania. com/2011/12/solenoid.html, 20 April 2012 10.07 WIB

Budiharto, Widodo. 2006. Belajar Sendiri Membuat Robot Cerdas. Bekasi: Elex Media Komputindo.

Budiharto, Widodo \& Gamayel Rizal. 2006. Belajar Sendiri 12 Proyek Mikrokontroler Untuk Pemula. Bekasi: Elex Media Komputindo.

Budiharto, Widodo \& Sigit Firmansyah. 2004. Elektronika Digital dan Mikroprosesor. Jakarta: Penerbit Andi. 